\title{
Methodological efficiency of using virtual and augmented reality in the educational process
}

\author{
Yulia Lebedeva ${ }^{1}$, Yulia Belozerova $^{2, *}$, Maria Zakharova $^{3}$, Maria Volkova $^{3}$ \\ ${ }^{1}$ State University of Management, Ryazanskiy prospect, Moscow, 109572, Russian \\ ${ }^{2}$ The Institute of cinema and TV (GITR) (ex named The Humanities Institute of TV and Radio \\ Broadcasting), 32A Khoroshevskoye road, Moscow, 123007, Russia \\ ${ }^{3}$ Innovations and technologies in education and science LTD, 125, Varshavskoe road, Moscow, \\ 117857, Russia
}

\begin{abstract}
This article presents the results of an experiment on creating an electronic textbook for universities and programs of additional professional education using virtual and augmented reality technologies and evaluating the results of testing the textbook on the basis of the State University of Management. The topic of the electronic textbook concerns the organization of the security service of accommodation facilities. The authors provide a description of the electronic textbook, its structure, main interactive elements, the progress of work, talk about the difficulties that they encountered. The working group on the creation of the textbook included methodologists, psychologists, specialists from the security services of Moscow hotels and specialists in information technology. Teams of key developers - the State University of Management, the Lotte group of companies, the LLC ITRON limited liability company, and the Rusays Publishing House - worked in partnership. Conclusions are made about the possibilities of using virtual and augmented reality technologies in educational activities. Augmented reality technology is used to create a mobile application that displays educational materials with reference to reallife objects according to special markers. This technology allows you to make the textbook unique for a specific object (office, building, structure, landscape). The results of the training using an electronic participant are presented. The peculiarities of the psychological perception of educational material and the effectiveness of the new format of presentation of the educational environment are noted.
\end{abstract}

\section{Introduction}

The educational process is more and more tending towards digitalization, information technologies in the broadest sense are being introduced into education, and education is being ironed out: filling education with new meanings, dimensions and spaces.

Skill training and the development of personality traits come first compared to learning and knowledge transfer. Knowledge is easily devalued, obsolete, and ceases to be relevant. Skills, like personality traits, are constantly evolving, but constant.

\footnotetext{
*Corresponding author: avuzto@yandex.ru
} 
One of the most striking and methodologically poorly studied technologies and vectors for the development of education is the introduction of virtual and augmented realities into the educational process. These technologies affect not so much the amount of knowledge, but rather the adaptation of knowledge to practical use, the integration of knowledge into practice, focusing on the psychological characteristics of the individual.

This article presents the results of an experiment on the creation of an electronic textbook for universities and programs of additional professional education using virtual and augmented reality technologies and evaluating the results of testing the textbook on the basis of the State University of Management and LLC ITRON.

Virtual reality (VR) is an artificial computer simulation or recreation of a real life environment, situation. It can be created by software for both individual technical means and for smartphones, which, being inserted into special helmets and fixed close in front of the eyes (the image is created for each eye separately), place the listener in a completely simulated reality, primarily influencing his organs perceptions such as sight and hearing.

Virtual space - the space of communications, social networks, messengers on the one hand, equality of communicators with undefined competencies - on the other, leads to a very specific educational situation.

Virtual reality is a set of realities, situations, locations in which a listener or a group of listeners can be placed. To develop the competence of the listener in the space of his potential workplace: a specific plant, office, control panel of a hydroelectric power station, etc.

Virtual reality provides an opportunity for interdisciplinary learning, when different teachers set the parameters of their subject in a single situational space. The skills developed easily integrate students into practical work, thereby bringing the educational institution and potential employer closer together, uniting them at one point.

What are these opportunities and how to evaluate and understand them?

\section{Methods}

One of the most interesting incarnations of virtual reality in terms of research and development of methodological vectors for the development of educational processes is the creation of electronic teaching aids.

In 2019, as part of the implementation of the state contract with the Federal Agency for Tourism, the State University of Management created a working group and attracted coexecutors to create an electronic textbook on organizing the work of the security service in accommodation facilities.

The working group for the creation of the textbook included methodologists, psychologists, specialists from the security services of Moscow hotels and specialists in information technology. Teams of key developers - the State University of Management, the Lotte group of companies, the limited liability company "INTERACTIVE TECHNOLOGIES AND SOLUTIONS IN EDUCATION AND SCIENCE” (LLC ITRON), Publishing House Rusays, worked in partnership. This partnership alliance has previously shown its effectiveness, including in the implementation of the National system for training and advanced training of tourism industry specialists in the period from 2015 to 2018, where more than 40 thousand employees of hotels and travel agencies were trained in distance and full-time formats [1].

In general, management issues in the service sector, including training, education, were developed by the team of authors for a long time and the main conclusions are reflected in articles, textbooks and monographs. [2,3,4].

This time, the development covered several aspects. The team created an electronic textbook "Organization of the work of the security service of the accommodation facility". The textbook included both lectures in the format of video clips and presentations, and 
innovative sections - a section of virtual reality (VR) and a section of augmented reality (AR) (Fig. 1).
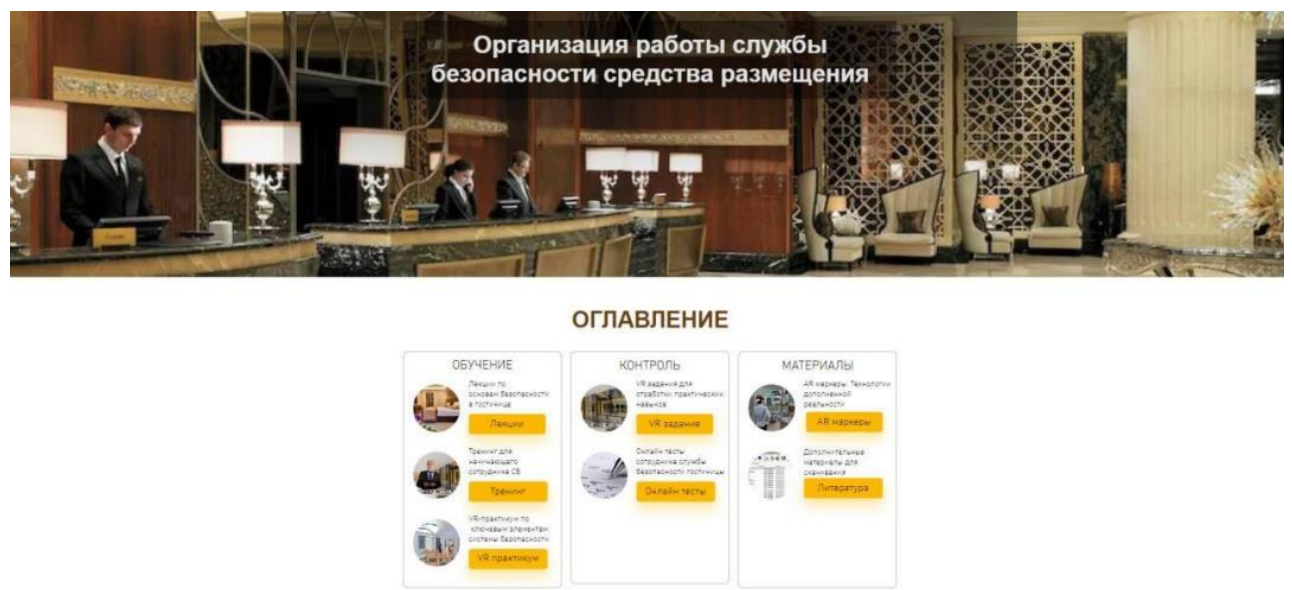

Fig. 1. The main page of the electronic textbook.

This article is devoted to the educational and methodological value of these two sections.

How were the VR and AR sections of the tutorial created?

A 3D model of the hotel was created, rather conventional, but at the same time possessing all the necessary attributes of a real hotel, which are important for demonstrating the work of the security service. The virtual hotel consisted of an entrance, reception and accommodation counter, a lobby, a bar counter and a cafe with tables, an elevator and stairs to the second floor (Fig. 2).
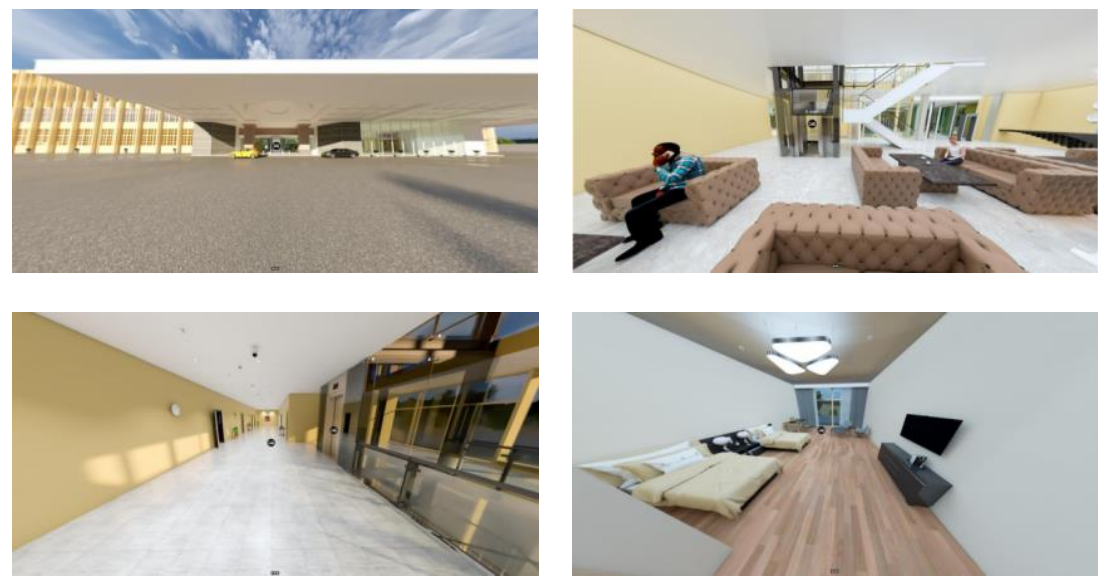

Fig. 2. 3D model of the hotel.

On the second floor there is a corridor and two open standard rooms. Each has a bathroom, a bed, windows, TVs, paintings, wardrobes and so on, everything that is necessary for any hotel and differs only in design.

The hospitality business assigns a very wide range of areas of responsibility to the security service. From slippery floors to observing challenging guests, the quality of glass, carpets and so on are all a matter of security concern and responsibility. All basic and typical hotel attributes were implemented in the 3D model. 
A short video was shot for each area of responsibility of the security service, in which it was as concise and concentrated as possible, but not to the detriment of its meaning, it was told what exactly the security personnel should pay attention to.

The thickness and tempering parameters of the glass, at what angle the windows can be opened, what requirements the bathroom rug should meet, and so on The videos corresponded to thematically key features of one point or another on the hotel model. The duration of such videos is from 15 seconds to 1 minute 20 seconds. It is important that the information is presented as concisely as possible.

Virtual reality was assembled from a 3D model of the hotel. That is, the user could navigate the hotel without additional software. This requires a regular browser. In the desktop version, you can navigate with the mouse. In addition, there is a version for virtual reality glasses.

When considering the platform and technology for implementation in virtual reality, preference was given to the universality of application. So that there is no need to purchase additional expensive equipment, but to implement the use of virtual reality using typical equipment and inexpensive helmets. Virtual reality glasses are a closed plastic or cardboard helmet, inside which a smartphone with the necessary software is placed. Lenses are located between the smartphone and the face and the image is transmitted synchronously, and, most importantly, independently to both eyes. Recommendation - ITRON-VR-Cardboard cardboard glasses 2.2 .

\section{Results}

The developed textbook allows you to listen to and view lectures and trainings describing the principles of organizing a security service in accommodation facilities, and then start learning in virtual reality.

In fact, an innovative concept of the electronic training manual "Organization of the security service of the accommodation facility" was developed, based on the latest technologies of augmented and virtual reality, created for a more effective form of practicing practical situations.

The textbook helps to increase student engagement in the subject. The electronic training manual "Organizing the work of the security service of the accommodation facility" uses interactive technologies that imply the expansion of opportunities for learning using audio, video and graphics.

The electronic course uses virtual reality technology - a world created by technical means, transmitted to a person through his sensations: vision, hearing, touch and others. Virtual reality simulates both exposure and responses to exposure. To create a convincing complex of sensations of reality, computer synthesis of properties and reactions of virtual reality is performed in real time. What increases the emotional engagement of listeners, as shown by the work of Hoffman- Klotzsche [3].

The virtual reality objects are the hotel and its main standard premises: lobby, elevator, flight of stairs, corridor, living rooms. Virtual reality objects look close to the behavior of similar objects in material reality.

The e-course also includes the use of augmented reality technology - the result of introducing any sensory data into the field of perception in order to supplement information about the environment and improve the perception of information. The use of these innovative technologies is justified from the standpoint of teaching methodology, the effectiveness of educational methods and facilitating the perception of information by students.

When using the textbook, it is possible to use two versions of the program - telephone and computer (the telephone version is adapted for Android and iOS). 
The tutorial contains the following sections:

1. Initial theoretical training for the security officer of the accommodation facility in two parts.

2. Practical virtual training on a model accommodation facility.

3. Control tasks of two types (summary test, with a system of questions and answer options and VR - assessment of the behavior of listeners in virtual reality.).

The tutorial contains a course of video lectures on the basics of security of accommodation facilities, training for a novice security officer, a workshop in connection with objects of a virtual environment, practical control tasks in a virtual environment, electronic testing, markers and a mobile augmented reality application, presentations and educational and methodological developments available for download.

The listener independently with the help of the textbook listens to the training lectures, passes the practical part of the training in a virtual accommodation facility. After that, he proceeds to control tasks and tests.

In the face-to-face classes, students are provided with the opportunity to use specialized augmented and virtual reality glasses.

Also presented is a portfolio of markers and the ability to stick them in the necessary places. That is, in each specific hotel, you can print markers, stick them and when you point the phone (augmented and virtual reality glasses) at the marker in the phone, the video tied to the marker and point will also be turned on.

Within the framework of the project, classes were held on the basis of the State University of Management. Security officers were trained theoretically within the course, and in the classroom they underwent a training workshop and training in virtual reality (Fig. 3). The number of subjects was 120 .

The subjects in the face-to-face lesson using the electronic training manual had to go through the entire virtual hotel, listening to video inserts describing the problems of each marked point.

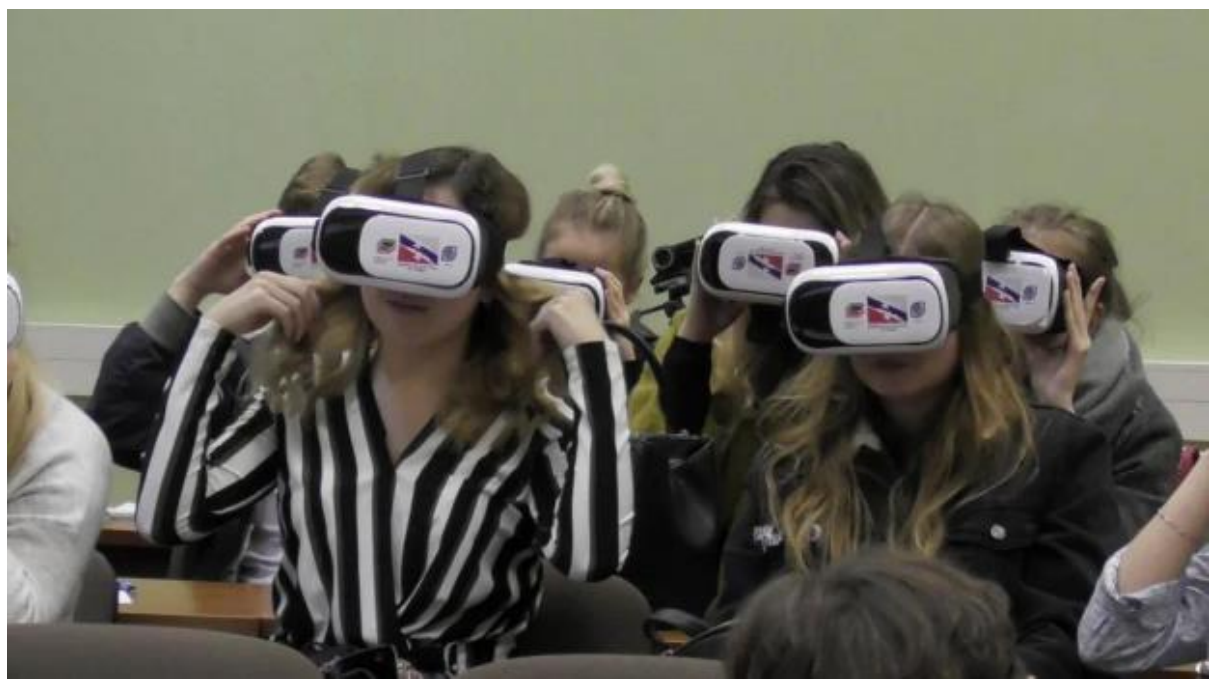

Fig. 3. Approbation of an electronic textbook using virtual reality glasses.

Before the first lesson, a survey was conducted of the audience.

The questionnaire asked questions related to the methodological features of the textbook: is the student familiar with virtual reality, did he come across similar technologies in teaching, and how does he relate to the application of technology in education. 
Not a single listener in practice has encountered virtual reality before. 12 percent of the subjects had heard about this technology, but had no idea what exactly it is. Prior to using the textbook, technology skepticism was over 74 percent. Only 26 percent (31 out of 120 respondents) immediately replied that they were ready to try, and only 7 people (6 percent of the respondents) took this opportunity with enthusiasm.

During the training, the first experience of entering virtual reality was difficult for many. The listeners put on their glasses and took them off immediately, and put them on again after a few minutes. To complete the course, the trainees had to complete the entire training, and this was a stimulating factor to continue the experiment. After a while, all listeners were quite comfortable with the virtual reality glasses. They did not cause discomfort. The navigation was clear. Each listener could compare a computer trip around the hotel and a trip in a helmet.

After completing the workshop, the students moved on to training in virtual reality.

After the trainees completed their familiarization with the description of the points, what exactly needs to be paid attention to, how exactly and what needs to be responded to, they were offered a training workshop. What was the task?

Wearing a virtual reality helmet, the listeners found themselves in the same hotel, but without prompts. At the same time, the application itself changed the dynamic parameters of the hotel in a random order. That is, it brought violations into the hotel: a forgotten phone, a burning cigarette, the indicator of how many floor is not in place, the missing evacuation scheme, a telephone and a rug in the bathroom, fire safety sensors, marks on glass, and so on. The listener had to patrol the hotel, identify all violations and write a report, in which it is necessary to indicate the violations themselves, as well as their decisions made and describe the necessary actions. Within the framework of the first version of the textbook, various scenarios were not laid down: the necessary medical assistance for the guest in the lobby, in the room, fire in the room, and so on. At the moment, the development of the textbook is being considered in this direction, which will enrich the practical value and usefulness of the textbook.

The training did not cause any methodological or technical difficulties.

The listeners patrolled, but from the first time only 18 listeners (15\%) managed to find all the violations - all the rest missed one or more violations, the problem of writing reports also arose: the listeners did not know the rules of their actions.

A pause was announced by the methodologists, in which the listeners again needed to study the teaching materials.

After that, the training was carried out again.

Success has skyrocketed. Found all violations already at least (60 people, 50 percent). Approximately 78 percent of the listeners had a correct response to violations in accordance with the regulations (93). Despite the fact that violations changed in a random order, but attentiveness increased, reactions and actions in response to violations were determined by the rules.

The poll showed that 40 people ( $33 \%$ of the listeners) faced some of the violations for the first time. They have not encountered them in practice. In the opinion of the methodologists, in fact, the subjects previously simply did not pay attention to some nuances in the security system of real hotels, which they had a chance to visit.

To the question "What is the effectiveness of interactive e-learning under the program" Organization of the security service of the accommodation facility ", the respondents most often noted:

- allow to make classes exciting, interesting (34\%);

- contribute to more efficient handling of practical situations (30\%);

- involvement in the cognitive process increases (27\%).

Thus, it can be assumed that the use of virtual and augmented reality technologies is promising for the field of vocational training. Especially in the field of management [3]. 


\section{Discussion}

We see that the effectiveness of virtual reality is primarily related to the connection between theoretical training and its practical application. Students were able to integrate their practice at work, theoretical material, regulations and the simultaneous application of all this.

Virtual reality is the key to practical awareness and maximum use of theoretical training in practical working life $[4,5,6]$.

But the tutorial was not limited to virtual reality. An augmented reality application was also created. What does this mean?

Augmented reality (AR) is a technology that allows visual objects and additions created on a computer to be superimposed on existing objective reality, but this content is not tied to it or is not part of it.

Augmented reality allows you to display instructions, comments, depending on the context of reality and the actions of the listener. It allows you to interact with virtual objects in the same way as with physical objects using sensors, control panels, and so on. Augmented reality can be introduced into the educational process not only as a university part of training, but also as a practical one at enterprises and organizations. Virtual and augmented reality in one space (mixed reality) give an extraordinary effect, the scale of which has yet to be realized. Managing not only space, but also psychological circumstances helps to develop a variety of competencies, get rid of psychological blocks and barriers $[7,8]$.

Within the framework of the electronic textbook "Organization of the security service of the accommodation facility", augmented reality was implemented as follows. Short videos, in which, in the most concise and concentrated way, but not to the detriment of meaning, tell what exactly it is necessary to pay attention to security personnel, posted in an augmented reality application and tied to a marker. A marker is a graphic image of any size and resolution (in this case, $50 \times 50 \mathrm{~mm}$ ).

By turning on the application on the smartphone, the rear camera is automatically turned on on it, and by pointing the image shown by the camera to the marker, the application calls the video associated with the marker. The marker can be glued or otherwise placed in the place of the real hotel, which the video corresponds to. For example, if the video deals with the points of concern of the security service in the bathroom, then you can attach a marker on the floor, walls, near a switch or outlet. And any security officer will be able, seeing the marker itself, to pay attention - this is a point of concern, and by activating the application on the smartphone and pointing it at the marker, see a short video with instructions on what to look for, how to behave in case of violation of standards, etc. P. This is especially true for new employees. Especially when it comes to creating an innovative infrastructure for the tourist business, personnel training should also be carried out using innovative methods [9, $10,11]$.

Thus, augmented reality provides an e-textbook with an amazing ability to adapt to any type of placement. Without even taking a course, simply installing an augmented reality application, any security officer is next to a coach who prompts at every point - what and how to do, where to look, how to act.

Markers can be printed from the file attached to the textbook and placed, pasted, attached in all necessary places. Thus, the textbook has another dimension: it goes beyond the program and covers a wide variety of hotels and accommodation facilities, integrates into the relief of hotels without geographical restrictions and expands the audience potentially to all security personnel of all interested hotels [12]. 


\section{Conclusions}

Virtual and augmented reality have enormous methodological potential. Like everything new, they face resistance from consumers, teachers, and methodologists. But when listeners overcome resistance and step over the psychological barrier of an unusual way of teaching, then most are completely satisfied with the result.

The real sectors of the economy are in need of training courses in virtual and augmented reality. The market for such courses will change the entire educational landscape beyond recognition [13].

The main problem today is the lack of specialists in creating virtual and augmented reality, and not technical ones, this does not cause difficulties, but methodologists, screenwriters, playwrights of the educational process. These are new specialties at the intersection of pedagogy, psychology and technology. However, it is also necessary to remember about the high costs associated with the development of such a course, about investment risks [14,15], which so far limit the flow of investments of educational organizations in the creation of such high-tech solutions.

But modern tools are actually able to simplify and reduce the cost of the process of preparing innovative educational content, the main thing is the idea and the project team.

\section{References}

1. Y.M. Belozerova, Razvitiye turizma $v$ kontekste innovatsionnykh protsessov sovremennoy ekonomiki: sbornik materialov mezhdunarodnoy nauchno-prakticheskoy konferentsii (Yeletskiy gosudarstvennyy universitet im. I. A. Bunina, Yelets, 2018)

2. S.M. Hofmann, F. Klotzsche, A. Mariola, V.V. Nikulin, A. Villringer, M. Gaebler, EEG Using LSTMS Proceedings - 2018 IEEE International Conference on Artificial Intelligence and Virtual Reality, Aivr 2018 (Institute of Electrical and Electronics Engineers Inc., 2018)

3. P. Buń, J. Trojanowska, P. Rewers, VR and AR in Lean Manufacturing Classes Faculty of Mechanical Engineering and Management, Poznan University of Technology (Poznań, 2019)

4. E. Peillard, J.M. Norrnand, G. Moreau, T. Thebaud, F. Argelaguet, A. Lecuyer, 26th IEEE Conference on Virtual Reality and 3D User Interfaces, VR 2019 - Proceedings, 26 (Institute of Electrical and Electronics Engineers Inc., 2019)

5. C. Eichhorn, D.A. Plecher, G. Klinker, M. Inami, 26th IEEE Conference on Virtual Reality and 3D User Interfaces, VR 2019 - Proceedings 26 (Institute of Electrical and Electronics Engineers Inc., 2019)

6. R. Han, Z. Feng, X. Fan, T. Xu, J. Tian, J. Meng, Proceedings of 2020 IEEE 4th Information Technology, Networking, Electronic and Automation Control Conference, ITNEC, Institute of Electrical and Electronics Engineers Inc. (2020)

7. V. Simkovic, V. Zajicek, R. Hajtmanek, International Conference on Engineering Technologies and Computer Science: Innovation and Application, ENT, Institute of Electrical and Electronics Engineers Inc. (2019)

8. S.M. Hofmann, F. Klotzsche, A. Mariola, V.V. Nikulin, A. Villringer, M. Gaebler, Proceedings - 2018 IEEE International Conference on Artificial Intelligence and Virtual Reality, AIVR 2018, Institute of Electrical and Electronics Engineers Inc. (2018)

9. I. Stanica, M.I. Dascalu, C.N. Bodea, B.A.D. Moldoveanu, Zooming Innovation in Consumer Technologies Conference, ZINC 2018 (Institute of Electrical and Electronics Engineers Inc., 2018) 
10. O.P. Pinchuk, V.A. Tkachenko, O.Y. Burov, Proceedings of the 15th International Conference on ICT in Education, Research and Industrial Applications. Integration, Harmonization and Knowledge Transfer (2019)

11. D. Rath, I. Satpathy, B.C.M. Patnaik, International Journal of Innovative Technology and Exploring Engineering 2278-3075, 3228-3236 (2019)

12. R. Yung, C. Khoo-Lattimore, L.E. Potter, E-Review of Tourism Research (Texas A, M University, 2019)

13. X.T. Huang, Z.D. Wei, X.Y. Leung, Asia Pacific Journal of Tourism Research (Routledge, 2020)

14. A. Khaitov, V. Gazieva, N.P. Isxakova, N.X. Latipova, International Conference On Information Science and Communications Technologies: Applications, Trends and Opportunities, ICISCT 2019 (Institute of Electrical and Electronics Engineers Inc., 2019)

15. N.F. Murodillayevich, U.G. Eshpulatovich, J.O. Pardaboyevich, International Conference On Information Science and Communications Technologies: Applications, Trends and Opportunities, ICISCT 2019 (Institute of Electrical and Electronics Engineers Inc., 2019) 